\title{
Serum screening for oncogene proteins in workers exposed to PCBs
}

\author{
P W BRANDT-RAUF,' H L NIMAN ${ }^{2}$ \\ From Occupational Medicine,' Columbia-Presbyterian Medical Center, New York, NY, and Department of \\ Molecular Biology, ${ }^{2}$ Research Institute of Scripps Clinic, La Jolla, CA, USA
}

\begin{abstract}
A cohort of 16 municipal workers engaged in cleaning oil from old transformers was examined for possible health effects from exposure to polychlorinated biphenyls (PCBs). In addition to the evaluation of routine clinical parameters (history, physical examination, liver function tests, serum triglycerides, serum PCB values), a new screening technique for the presence of oncogene proteins in serum using monoclonal antibodies was used to ascertain the potential carcinogenic risk from exposure in these workers. Except for one individual, serum PCB concentrations were found to be relatively low in this cohort, probably due to the observance of appropriate protective precautions. The results of liver function test were within normal limits and serum triglyceride concentrations showed no consistent relation to PCB concentrations. Six individuals, all of whom were smokers, showed abnormal banding patterns for $f e s$ oncogene related proteins. The individual with the highest serum PCB concentration also exhibited significantly raised levels of the H-ras oncogene related P21 protein in his serum. These oncogene protein findings may be indicative of an increased risk for the development of malignant disease in these individuals.
\end{abstract}

Polychlorinated biphenyls (PCBs) are a group of cholorinated aromatic hydrocarbons extensively used in the past in transformer and capacitor fluids, plasticisers for surface coatings, pump oils, hydraulic systems, printing inks, flame retardants, extenders for pesticides, and copy paper. ${ }^{12}$ PCBs have been of concern in environmental and occupational health because of this widespread use, a low degree of biodegradability, and well recognised acute and chronic toxic effects. ${ }^{1-3}$ PCB poisoning was first described in detail in two large epidemics in China and Japan (Yu Cheng and Yusho diseases, respectively) caused by the ingestion of contaminated cooking oil. ${ }^{34}$ This syndrome included oculodermatological symptoms with chloracne, neurophysiological abnormalities of a primarily sensory neuropathy, constitutional symptoms, reproductive effects, and clinical biochemical findings (raised liver function test results and serum triglycerides) ${ }^{34}$ Investigations of occupationally exposed populations have identified clinical abnormalities of lesser severity including chloracne and raised liver function test results and serum triglycerides. ${ }^{124}$ The major concerns of chronic toxicity from PCBs have been their potential carcino-

Accepted 2 November 1987 genicity based on their positive response in in vitro cell transformation assays and their demonstrated ability to produce liver tumours in rats at relatively low doses; however, occupational cancer mortality studies of exposed workers are inconclusive. ${ }^{1247}$

In the autumn of 1986 several dozen local municipal workers were engaged in removing fluid containing PCBs from transformers and cleaning up resultant spills. Despite appropriate protective precautions, it was thought that some of the workers may have had significant exposure. Therefore, these workers were referred to Columbia-Presbyterian Medical Center for medical surveillance and monitoring; in addition to routine $\mathrm{PCB}$ surveillance measures (history, physical examination, liver function tests, serum triglycerides, serum PCB concentrations) selected workers were screened using a new technique for detecting serum oncogene proteins in an attempt to study the issue of potential carcinogenicity of PCBs in exposed human populations. This report represents our preliminary findings.

\section{Methods}

Two dozen local municipal workers were engaged in removing and cleaning up old transformers containing PCBs (about $600000 \mathrm{ppm}$ in the transformer oil) over 
several months in the autumn of 1986 . This work entailed containing and eliminating spilled fluid from leaking transformers and draining and removing the PCB containing oil from the transformers. Some inadvertant exposure of the workers occurred, especially through primary dermal contact or secondary dermal contact from contaminated clothing or shoes. These workers were referred for medical surveillance. On further questioning as to the degree of potential exposure, 16 workers were selected for complete evaluation. This evaluation included the following: complete medical and occupational history including other possible sources of exposure to PCBs (including past work experience, ingestion of fresh water fish from contaminated sources and hobbies) and other exposure to hazardous materials, in particular carcinogens such as asbestos or cigarettes; complete physical examination with particular reference to the dermatological examination; and laboratory tests by routine techniques for serum triglycerides, serum PCB concentrations, and liver function tests (SGOT, SGPT, LDH, alkaline phosphatase, bilirubin; workers were requested to refrain from consuming ethanol for two weeks before testing and to have no oral intake on the day of testing).

In addition, these workers were evaluated for the presence of oncogene related proteins in their serum by an adaptation of the urine immunoblotting techniques of Niman et al. ${ }^{8}$ For the assay, $100 \mu$ l of serum was mixed with $400 \mu \mathrm{l}$ phosphate buffered saline (PBS)

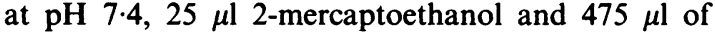
sample buffer in deionised water $(6 \cdot 25 \%$ sodium dodecyl sulphate, $6.25 \%$ glycerol), and placed in a bath of boiling water for five minutes. Samples were then loaded on a $5-17 \%$ polyacrylamide gel and electrophoretically separated and transferred to nitrocellulose. After blocking with PBS containing 3\% bovine serum albumin and $0.1 \%$ Triton $\mathrm{X}-100$, the nitrocellulose was incubated overnight at $4{ }^{\circ} \mathrm{C}$ with monoclonal antibodies directed against synthetic peptides representing predicted oncogene sequences (ascites fluid diluted 1:2000) After washing three times, the nitrocullulose was incubated with rabbit antimouse IgF (1:500) for 60 minutes at room temperature. After three more washes, the nitrocellulose was incubated with ${ }^{125}$ l-labelled protein $A\left(10^{6} \mathrm{cpm} /\right.$ $\mathrm{ml}$ ). Binding was visualised with intensifying screens. The primary antibodies used were directed against protein sequences of the following oncogenes (see figure): sis (lane 1, hybrid 112-09B10, sequence SLGSLTIAEPAMIAEC); fes (lane 2, hybrid 127-42C11 and lane 3, hybrid 127-50D04, sequence LMEQCWAYEPGQRPSF; lane 15, hybrid 121-14C09, sequence IGRGNFGEVFSG(C)); $\beta$-TGF (lane 4, hybrid 100-30C05 and lane 5, hybrid 100-34E06, sequence ALDTNYCFSSTEKNC); int-1 (lane 6, hybrid 222-35C08 and lane 12, hybrid 222-37F04, sequence LHNNEAGRTTVFS(C)); myb (lane 7, hybrid 133-10F06, sequence LGEHHCTPSPPVDHG); src (lane 8, hybrid 203-07D10, sequence (C)GSSKSKPKDPSQRRHS); c-myc (lane 9, hybrid 155-11C07, lane 13, hybrid 155-08G01, and lane 14, hybrid 155-09F06, sequence CSTSSLYLQDLSAAASEC); mos (lane 10, hybrid 165-35F02, sequence LGSGGFGSVYKA(C)); H-ras (lane 11, hybrid 142-24E05, sequence YREQIKRVKDSDDVPMVLVGNKC and lane 16, hybrid 146-03E04, sequence YTLVREIRQHKLRKLNPPDESGPGC).

Summary of findings on workers exposed to PCBs

\begin{tabular}{|c|c|c|c|c|c|c|}
\hline \multirow[b]{2}{*}{ Patient } & \multirow[b]{2}{*}{ Total } & \multicolumn{5}{|c|}{ PCB concentrations } \\
\hline & & $\begin{array}{l}2,2^{\prime}, 3,3^{\prime}, 4,4^{\prime}, 5 \\
\text { Hepta }\end{array}$ & $\begin{array}{l}2,2^{\prime}, 3,4,4^{\prime}, 5,5^{\prime} \\
\text { Hepta }\end{array}$ & $\begin{array}{l}2,2^{\prime}, 3,4,4^{\prime}, 5^{\prime} \\
\operatorname{Hexa}\end{array}$ & $\begin{array}{l}2,2^{\prime}, 3,4,4^{\prime}, 5 \\
\operatorname{Hexa}\end{array}$ & $\begin{array}{l}2,2^{\prime}, 4,4^{\prime}, 5,5^{\prime} \\
\operatorname{Hexa}\end{array}$ \\
\hline $\begin{array}{l}1 \\
2 \\
3 \\
4 \\
5 \\
6 \\
7 \\
8 \\
9 \\
10 \\
11 \\
12 \\
13 \\
14 \\
15 \\
16\end{array}$ & $\begin{array}{r}1 \cdot 0 \\
2 \cdot 2 \\
0 \cdot 6 \\
2 \cdot 8 \\
6 \cdot 3 \\
22 \cdot 2 \\
0.4 \\
1 \cdot 8 \\
3 \cdot 0 \\
6 \cdot 5 \\
0.3 \\
0.3 \\
2.0 \\
1.5 \\
4 \cdot 5 \\
0.9\end{array}$ & $\begin{array}{l}- \\
- \\
- \\
- \\
0.6 \\
- \\
- \\
- \\
- \\
- \\
- \\
- \\
-\end{array}$ & $\begin{array}{l}- \\
- \\
- \\
1.3 \\
1.9 \\
2.0 \\
\overline{0.4} \\
2 \cdot 1 \\
2.3 \\
0.3 \\
- \\
0.3 \\
- \\
0.5 \\
-\end{array}$ & $\begin{array}{l}0.5 \\
0.8 \\
0.6 \\
0.8 \\
1.5 \\
5.2 \\
- \\
0.6 \\
0.3 \\
1.6 \\
- \\
- \\
0.6 \\
0.6 \\
1.1 \\
0.9\end{array}$ & $\begin{array}{l}- \\
- \\
- \\
- \\
- \\
0.4 \\
- \\
- \\
- \\
- \\
- \\
- \\
0.4 \\
0.4 \\
0.3 \\
-\end{array}$ & $\begin{array}{l}0.5 \\
0.8 \\
- \\
0.7 \\
1.7 \\
3.6 \\
0.4 \\
0.8 \\
0.6 \\
1.8 \\
- \\
0.3 \\
0.7 \\
0.5 \\
1.6 \\
-\end{array}$ \\
\hline \multicolumn{7}{|c|}{$\begin{array}{l}\text { WNL Within normal listing. } \\
- \text { Negative; }+ \text { Weakly positive; }++ \text { Moderately positive; }+++ \text { Strongly positive. }\end{array}$} \\
\hline
\end{tabular}


Results and discussion

The results are presented in the table. The cohort consisted of 16 white men with an average age of 42 (range $=27-65$ ). All reported some dermal contact with the PCB containing transformer oil during this work period; in addition, two had had prior potential exposure to PCB containing transformer oil over the past 20 years (patients 9 and 10). Seven workers reported having worked with other carcinogenic materials in the past; this was primarily exposure to asbestos from insulation handling, although one also had significant work exposure to chlorinated hydrosolvents and ionising radiation (patient 14). Twelve of the workers were current cigarette smokers or recent ex-smokers (within the past five years) and four had never smoked. Two individuals reported having acneiform lesions on the arms, legs, and feet shortly after exposure (patients 4 and 8 ), but physical examination showed no abnormalities consistent with exposure to PCBs in any of the workers.

In all cases results of liver function tests were within normal limits and in only three were the serum triglycerides raised. One individual (patient 8) had a high serum triglyceride concentration which had been reportedly normal in the past before exposure to PCBs; however, his serum PCB concentration was quite low. In the other two hypertriglyceridaemic individuals the prior status in terms of triglyceride concentrations was unknown, and their serum PCB concentrations were also relatively low. Furthermore, the individual with the highest serum PCB value had a normal triglyceride value. On the basis of these data, it is impossible to draw any conclusions regarding correlations between relatively low serum PCB concentrations and serum triglycerides, an association that has been noted with higher exposures to PCBs.'

As noted, overall serum PCB concentrations were low, attesting to the adequacy of protective measures taken. In general, concentrations less than $10 \mathrm{ppb}$ are not viewed with concern since such levels may often be identified in non-occupationally exposed normal controls. ${ }^{2}$ By this measure, only one individual (patient 6) could be considered to have a seriously raised serum PCB concentration.

The findings on serum oncogene protein screening are of interest. Half the workers showed some abnormality not noted in normal unexposed individuals. Six had abnormal banding patterns for fes oncogene related proteins. All had a positive smoking history ( $50 \%$ of total with a positive smoking history); none of the non-smokers displayed this pattern. Although the significance of this banding pattern is unknown at present, it is tempting to speculate that it may indicate those smokers at greater risk for neoplastic disease. One smoker also had an aberrant pattern for sis oncogene related proteins of unknown importance.

The patterns for the other oncogene proteins were normal except for ras. Three individuals had detectable levels of ras oncogene related proteins. In two of these cases the bands were relatively weak and there did not appear to be any connection to exposure; one had a PCB concentration of 6.5 with a positive smoking history and a positive history of other exposure to carcinogens (asbestos), and one had a PCB concentration of 0.3 and no other exposure history. One individual (patient 6), however, had an extremely aberrant pattern for Harvey ras oncogene related P21 protein (see lanes 11 and 16 in the figure;

\begin{tabular}{|c|c|c|c|c|c|c|c|c|c|}
\hline \multicolumn{3}{|c|}{ PCB concentrations } & \multirow{3}{*}{$\begin{array}{l}\text { Liver } \\
\text { function }\end{array}$} & \multirow{3}{*}{$\begin{array}{l}\text { Triglycerides } \\
(\mathrm{mg} / \mathrm{dl})\end{array}$} & \multirow{3}{*}{$\begin{array}{l}\text { History of } \\
\text { smoking }\end{array}$} & \multirow{3}{*}{$\begin{array}{l}\text { Other } \\
\text { carcinogen } \\
\text { exposure }\end{array}$} & \multirow{2}{*}{\multicolumn{3}{|c|}{ Serum oncogene proteins }} \\
\hline \multirow{2}{*}{$\begin{array}{l}2,3,3^{\prime}, 4,4^{\prime} \\
\text { Penta }\end{array}$} & \multirow{2}{*}{$\begin{array}{l}2,3^{\prime}, 4,4^{\prime}, 5 \\
\text { Penta }\end{array}$} & \multirow{2}{*}{$\begin{array}{l}2,3^{\prime}, 4,4^{\prime} \\
\text { Tetra }\end{array}$} & & & & & & & \\
\hline & & & & & & & fes & ras & sis \\
\hline- & - & - & WNL & WNL & Yes & No & - & - & - \\
\hline- & 0.6 & - & WNL & WNL & Yes & No & - & - & - \\
\hline- & - & - & WNL & WNL & Yes & No & $+t$ & - & - \\
\hline- & - & - & WNL & 193 & Yes & Yes & ++ & - & ++ \\
\hline- & $1 \cdot 2$ & - & WNL & WNL & No & No & - & - & - \\
\hline $2 \cdot 5$ & $7 \cdot 2$ & 0.7 & WNL & WNL & Yes & Yes & ++ & $++t$ & - \\
\hline- & - & - & WNL & WNL & Yes & No & ++ & - & - \\
\hline- & - & - & WNL & 597 & Yes & No & ++ & - & - \\
\hline- & - & - & WNL & 271 & Yes & Yes & ++ & - & - \\
\hline- & 0.8 & - & WNL & WNL & Yes & Yes & - & + & - \\
\hline- & - & - & WNL & WNL & No & No & - & + & - \\
\hline- & - & - & WNL & WNL & Yes & Yes & - & - & - \\
\hline- & - & - & WNL & WNL & No & Yes & - & - & - \\
\hline- & - & - & WNL & WNL & No & Yes & - & - & - \\
\hline 0.4 & 0.6 & - & WNL & WNL & Yes & No & - & - & - \\
\hline- & - & - & WNL & WNL & Yes & No & - & - & - \\
\hline
\end{tabular}




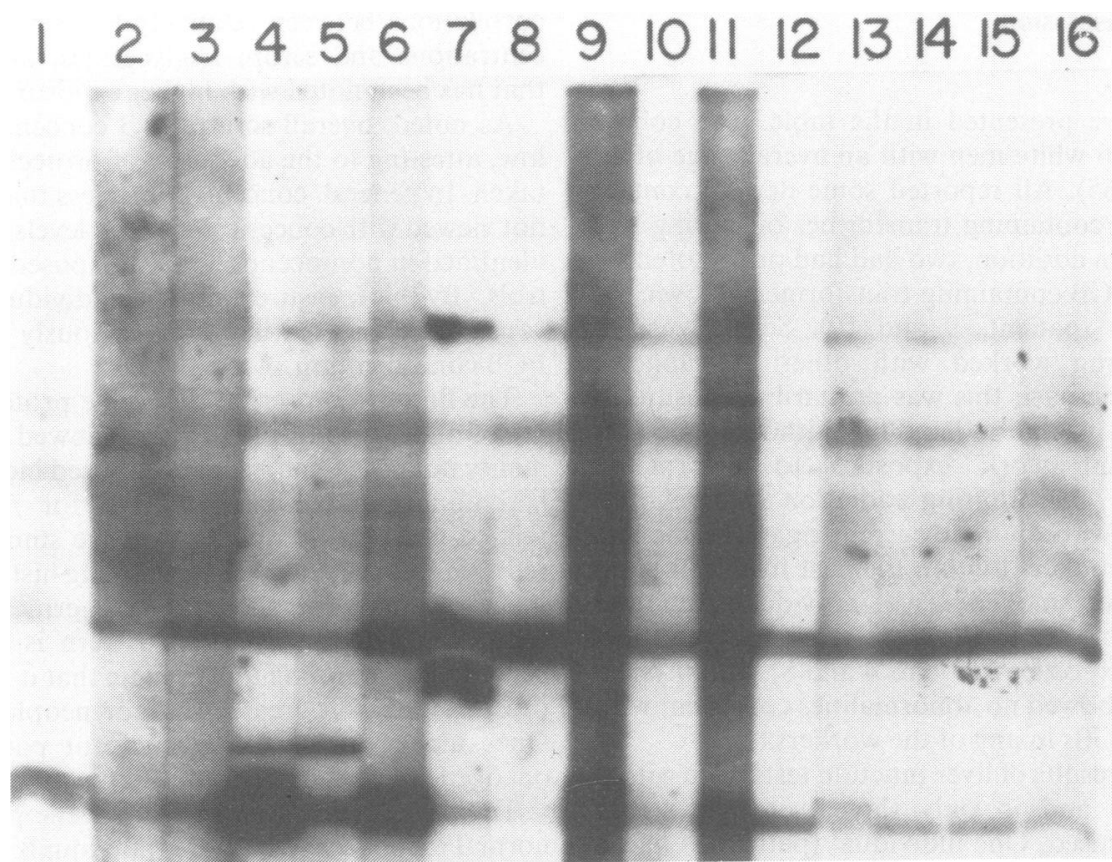

Fig 1 (a) Immunoblot of serum of normal, healthy control. Sample of $100 \mu \mathrm{l}$ of serum was probed with antibodies to peptide sequences predicted by following oncogenes: sis (lane 1), fes (lanes 2, 3, and 15), $\beta$-TGF (lanes 4 and 5), int- 1 (lanes 6 and 12), myb (lane 7), src (lane 8), $c$-myc (lanes 9, 13 and 14), mos (lane 10), and $\mathrm{H}$-ras (lanes 11 and 16).

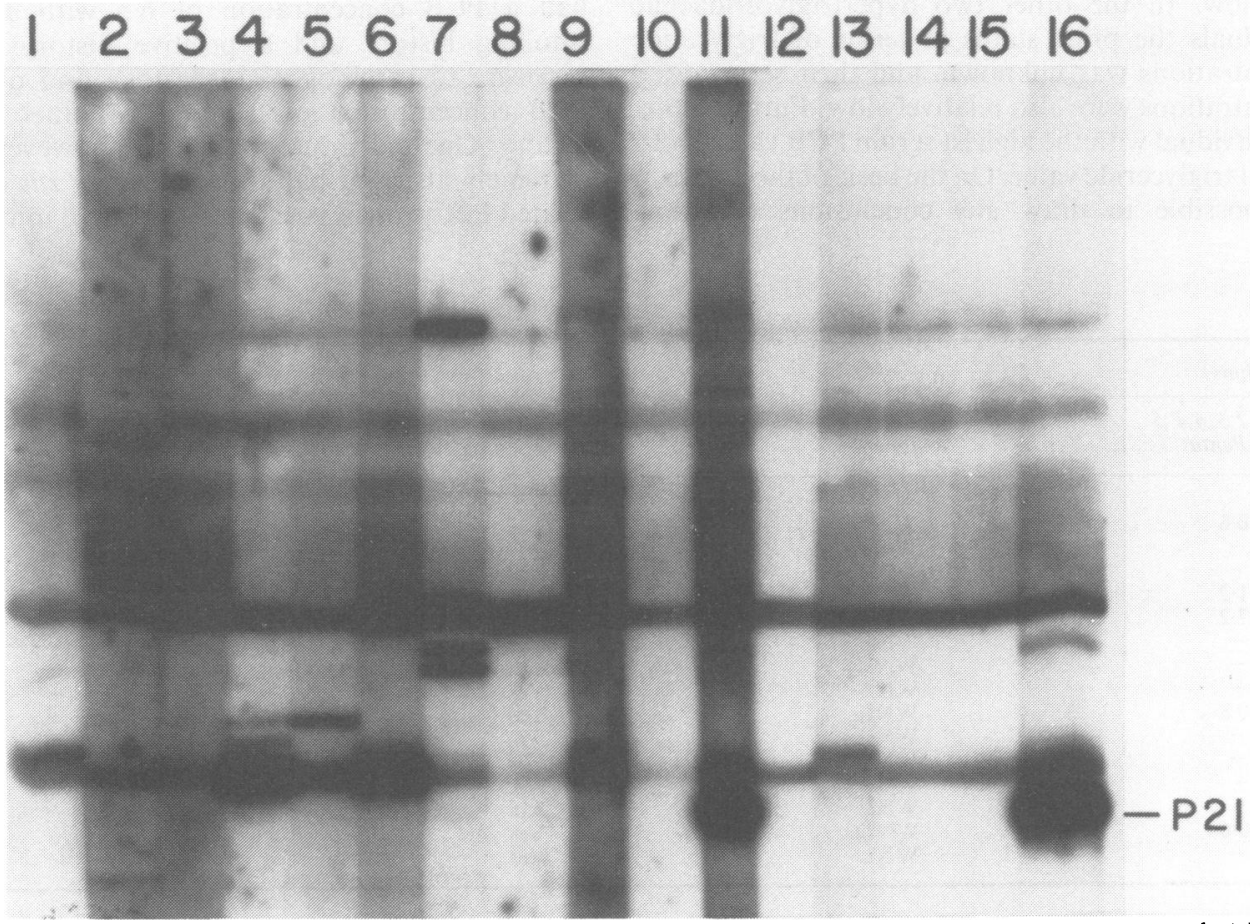

Fig 1 (b) Immunoblot of serum of individual with multiple carcinogen exposure (PCBs, asbestos, cigarette smoke) but with no clinically detectable malignant disease. Sample of 100 l of serum was probed with antibodies to peptide sequences predicted by oncogenes as defined in fig $1(a)$. Note presence of prominent lower bands in lanes 11 and 16 not found in normal, healthy control; these bands correspond to the Harvey ras oncogene encoded P21 protein. 
lane 11 was probed with broadly reactive antibody to the conserved central region of ras $\mathrm{P} 21$, and lane 16 was probed with Harvey ras specific antibody directed at the carboxyl terminal region of P21). It is interesting to note that this individual was the worker with the highest serum PCB concentration and also had a positive history for smoking and exposure to another carcinogen (asbestos). Once again, it is tempting to speculate on the importance of this finding. High levels of ras oncogene P21 protein are known to produce malignant transformation of NIH 3T3 cells in culture; this has been shown in transfection and microinjection experiments. ${ }^{10-12}$ High levels of expression of the ras oncogene have also been identified in a high percentage of tumour tissue from patients with cancers at a wide variety of sites and also in well recognised premalignant lesions such as colonic polyps. ${ }^{10-17}$ Therefore, this finding in an overtly clinically healthy individual with known exposure to carcinogens may represent an early marker of neoplastic disease. Collateral support for this presumption is derived from screening results in patients with cancer; in at least one case of a patient with breast cancer in remission recurrence of an abnormal oncogene protein pattern predated the reappearance of clinically detectable disease by several months. ${ }^{8}$

Further study of serum oncogene protein screening in occupationally exposed populations is clearly necessary before the use of this approach may be fully appreciated. In particular, what is needed is a long term study of a large cohort of workers exposed to carcinogens with detailed follow up of clinical outcome; such a study is being planned. This preliminary report, however, does show the applicability of this new technique for occupational cancer screening and indicates some of the potential power of this tool for the study of the molecular epidemiology of occupational carcinogenesis.

This work was supported in part by NCI grant CA38160(HLN) and NCI contract CP-4100976(HLN).

\section{References}

1 Letz G. The toxicology of PCBs-an overview for clinicians. West J Med 1983;128:534-40.

2 Fischbein A, Rizzo JN. Health effects of polychlorinated biphenyls (PCBs). Occupational Medicine Current Concepts 1984;7:1-4.

3 Kuratsune M, Shapiro RE. PCB poisoning in Japan and Taiwan. Am J Ind Med 1984;5:1-153.

4 Potential health effects of polychlorinated biphenyls and related persistent halogenated hydrocarbons: US symposium and workshop on occupational hazards caused by polychlorinated biphenyls and chlorobenzenes in capacitors and transformers: Finland-US symposium. Environ Health Perspect 1985;60: 3-352.

5 Norback DH, Swedo GJ. Transformation in vitro induced by Aroclor 1254: ultrastructure of transformed cells. Toxicol Appl Pharmacol 1979;48:A182.

6 Kimbrough RD, Squire R, Linder RE, Strandberg JD, Montali RJ, Burse VW. Induction of liver tumors in Sherman strain female rats by polychlorinated biphenyl (Aroclor 1260). JNCI 1975;55:1453-9.

7 Brown DP, Jones M. Mortality and industrial hygiene study of workers exposed to polychlorinated biphenyls. Arch Environ Health 1981;36:120-9.

8 Niman HL, Thompson AMH, Yu A, et al. Anti-peptide antibodies detect oncogene-related proteins in urine. Proc Natl Acad Sci USA 1985;82:7924-8.

9 Baker EL, Landrigan PJ, Glueck CJ, et al. Metabolic consequences of exposure to polychlorinated biphenyls (PCB) in sewage sludge. Am J Epidemiol 1980;112:553-63.

10 Brandt-Rauf PW, Pincus MR. Oncogenes and oncogene proteins. Occup Med 1987;2:27-38.

11 Chang EH, Furth ME, Scolnick EM, Lowy DR. Tumorigenic transformation of mammalian cells induced by a normal human gene homologous to the oncogene of Harvey murine sarcoma virus. Nature 1982;297:479-83.

12 Sigal IS, Gibbs JB, D'Alonzo JS, et al. Mutant ras-encoded proteins with altered nucleotide binding exert dominant biological effects. Proc Natl Acad Sci USA 1986;83:952-6.

13 Thor A, Horan-Hand P, Wunderlich D, Caruso A, Muraro R, Schlom J. Monoclonal antibodies define differential ras gene expression in malignant and benign colonic diseases. Nature 1984;311:562-5.

14 Hahib NA, Wood CB. The expression of ras oncogene in normal and pathological liver disease. Int Surg 1986;71:182-3.

15 Agnantis NJ, Petraki C, Markoulatos P, Spandidos DA. Immunohistochemical study of the ras oncogene expression in human breast lesions. Anticancer Res 1986;6:1157-60.

16 Slamon DJ, deKernion KB, Verma IM, Cline MJ. Expression of cellular oncogenes in human malignancies. Science 1984;224:256-62.

17 Spandidos DA, Kerr IB. Elevated expression of the human ras oncogene family in premalignant and malignant tumors of the colorectum. Br J Cancer 1984;49:681-8. 